Keywords: Polycomb group; truncation mutation; gene amplification; chromosomal translocation; histone modification; nuclear hormone receptor

\title{
Functional and cancer genomics of ASXL family members
}

\author{
M Katoh ${ }^{* 1}$ \\ ${ }^{1}$ Division of Integrative Omics and Bioinformatics, National Cancer Centre, 5-1-1 Tsukiji, Chuo Ward, Tokyo 104-0045, Japan
}

Additional sex combs-like (ASXL)1, ASXL2 and ASXL3 are human homologues of the Drosophila Asx gene that are involved in the regulation or recruitment of the Polycomb-group repressor complex (PRC) and trithorax-group (trxG) activator complex. ASXL proteins consist of ASXN, ASXH, ASXM1, ASXM2 and PHD domains. ASXL1 directly interacts with BAP1, KDM1A (LSD1), NCOA1 and nuclear hormone receptors (NHRs), such as retinoic acid receptors, oestrogen receptor and androgen receptor. ASXL family members are epigenetic scaffolding proteins that assemble epigenetic regulators and transcription factors to specific genomic loci with histone modifications. ASXL1 is involved in transcriptional repression through an interaction with PRC2 and also contributes to transcriptional regulation through interactions with BAP1 and/or NHR complexes. Germ-line mutations of human ASXL1 and ASXL3 occur in Bohring-Opitz and related syndromes. Amplification and overexpression of ASXL1 occur in cervical cancer. Truncation mutations of ASXL1 occur in colorectal cancers with microsatellite instability (MSI), malignant myeloid diseases, chronic lymphocytic leukaemia, head and neck squamous cell carcinoma, and liver, prostate and breast cancers; those of ASXL2 occur in prostate cancer, pancreatic cancer and breast cancer and those of ASXL3 are observed in melanoma. EPC1-ASXL2 gene fusion occurs in adult T-cell leukaemia/lymphoma. The prognosis of myeloid malignancies with misregulating truncation mutations of ASXL1 is poor. ASXL family members are assumed to be tumour suppressive or oncogenic in a context-dependent manner.

The Additional sex combs (Asx)-like 1 (ASXL1) gene (Fisher et al, 2003), ASXL2 gene (Katoh and Katoh, 2003) and ASXL3 gene (Katoh and Katoh, 2004) are human homologues of the Drosophila Asx gene, which was initially identified based on a mutant phenotype (appearance of ectopic sex combs on the legs) and then characterised as one of Polycomb group (PcG) genes that are required for long-term repression of homoeotic genes (Jürgens, 1985; Breen and Duncan, 1986; Simon et al, 1992; Sinclair et al, 1992, 1998).

Drosophila $P c G$ genes can be divided into classes based on their genetic and biochemical interactions (Simon et al, 1993; Cheng et al, 1994; Campbell et al, 1995; Brock and van Lohuizen, 2001; Grimaud et al, 2006; Sparmann and van Lohuizen, 2006; Simon and Kingston, 2009). The Drosophila Pc, Polyhomeotic, Sex comb on midleg, Posterior sex combs and Sex combs extra (Ring) genes encode core components of the Polycomb repressor complex 1 (PRC1). The Drosophila Extra sex combs, Enhancer of zeste and Suppressor of zeste 12 genes encode core components of the Polycomb repressor complex 2 (PRC2). The Drosophila Asx,
Calypso, Pleiohomeotic, Pleiohomeotic-like, dSfmbt and Polycomblike genes encode cofactors or regulators of PRC1 or PRC2. PRC2 is recruited to a specific genomic loci, where it catalyses the trimethylation of histone $\mathrm{H} 3$ at lysine 27 (H3K27me3). Polycomb repressor complex 1 is then recruited by the $\mathrm{H} 3 \mathrm{~K} 27 \mathrm{me} 3$ chromatin mark and catalyses the mono-ubiquitination of histone $\mathrm{H} 2 \mathrm{~A}$ at lysine 119, resulting in transcriptional repression of the PcG target genes (Schuettengruber et al, 2007; Schwartz and Pirrotta, 2007; Müller and Verrijzer, 2009). Polycomb-group repressor proteins have a key role in the maintenance of lineage-specific gene expression programs (Pietersen and van Lohuizen, 2008).

Most Asx mutants show posterior homoeotic transformation due to the loss of PcG functions, whereas several Asx mutants have been subsequently found to show not only posterior homoeotic transformations due to the loss of PcG functions but also anterior homoeotic transformations resulting from a loss of trithorax-group (trxG) functions (Milne et al, 1999; Brock and Fisher, 2005). Derepression of Drosophila $a b d A$ and $A b d B$ homoeotic genes is not so significant in the central nervous system (CNS) of Drosophila

*Correspondence: Dr M Katoh; E-mail: mkatoh-kkr@umin.ac.jp

Received 13 November 2012; revised 8 May 2013; accepted 10 May 2013;

published online 4 June 2013

(c) 2013 Cancer Research UK. All rights reserved 0007-0920/13

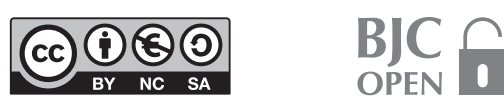


Asx mutants compared with other $P c G$ mutants (Simon et al, 1992). Derepression of $U b x$ homoeotic gene is also not significant in the CNS of most Asx mutants (Sinclair et al, 1998), whereas derepression of $U b x$ homoeotic gene occur in the wing blade of C-terminally deleted Asx mutant, which results in the wing defect phenotype (Bischoff et al, 2009). As Drosophila Asx has dual roles in the transcriptional regulation of homoeotic and non-homoeotic genes as a cofactor of both the PcG repressor complex and the trxG activator complex, Asx is involved in the transcriptional repression and activation of its target genes in a context-dependent manner (Sinclair et al, 1998; Gildea et al, 2000; Brock and van Lohuizen, 2001; Dietrich et al, 2001; Grimaud et al, 2006; Halachmi et al, 2007; Petruk et al, 2008).

Since the discovery of the human ASXL family genes in the early 2000s (Fisher et al, 2003; Katoh and Katoh, 2003, 2004), > 130 manuscripts on ASXL1, ASXL2 or ASXL3 have been published by various research groups worldwide (Figure 1A). The number of ASXL1 manuscripts drastically increased after a report described frequent ASXL1 mutations in human myeloid malignancies (GelsiBoyer et al, 2009). Truncation mutations of the ASXL1 gene frequently occur in myeloid malignancies, whereas amplification, translocation or point mutations of the ASXL1, ASXL2 or ASXL3 genes have been observed in other types of human cancers (Table 1). ASXL1 mutations in malignant myeloid diseases are reviewed elsewhere from a haematological point of view (Tefferi, 2010; Gelsi-Boyer et al, 2012). Large amounts of information on cancer genomics have been accumulated in the public database owing to innovation in nucleotide sequencing technology; however, data of cancer genomics themselves might look like printouts of 'laundry list' if not functionally annotated.
Here, functional and cancer genomics of the mammalian ASXL family genes are reviewed as the warp and woof of ASXL tapestry, respectively, to get bird's eye view of biological functions and genetic alterations of ASXL family members in human cancers. New insights and future directions of researches on the mammalian ASXL family will be described.

\section{ASXL FAMILY GENES}

The human ASXL gene family consists of three members: the ASXL1 gene is located at human chromosome 20q11.21 and is surrounded by KIF3B, DNMT3B and MAPRE1 genes; the ASXL2 gene is located at human chromosome 2 p23.3 and is surrounded by DNMT3A, DTNB, KIF3C, FAM59B and MAPRE3 genes; the $A S X L 3$ gene is located at human chromosome 18q12.1 and is surrounded by FAM59A, DTNA and MAPRE2 genes. As the ASXL family genes and the DNMT3, DTN, KIF3, FAM59 and MAPRE (sub)family genes are paralogues, the KIF3B-ASXL1 $\sim D N M T 3 B$ MAPRE1 locus, the DNMT3A-DTNB-ASXL2-KIF3C $\sim F A M 59 B \sim$

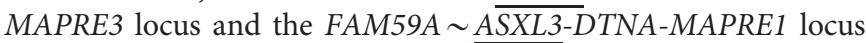
are paralogous regions within the human genome.

\section{ASXL FAMILY PROTEINS}

The human ASXL3 protein (2248 amino acids) is significantly larger than the human ASXL1 (1541 amino acids) and ASXL2 (1435 amino acids) proteins (Katoh and Katoh, 2004). The mouse and chicken Asxl3 orthologues are also significantly larger
A

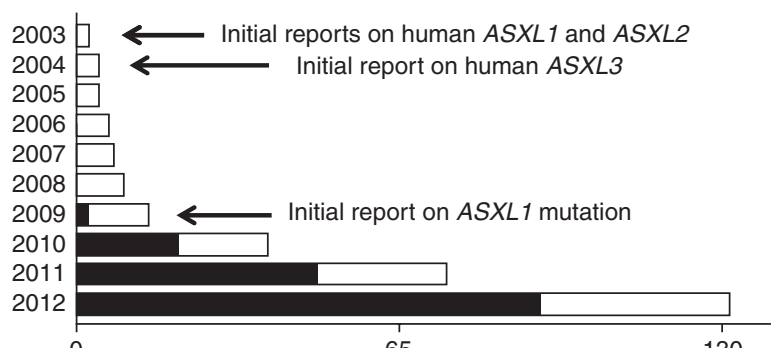

0

65

130
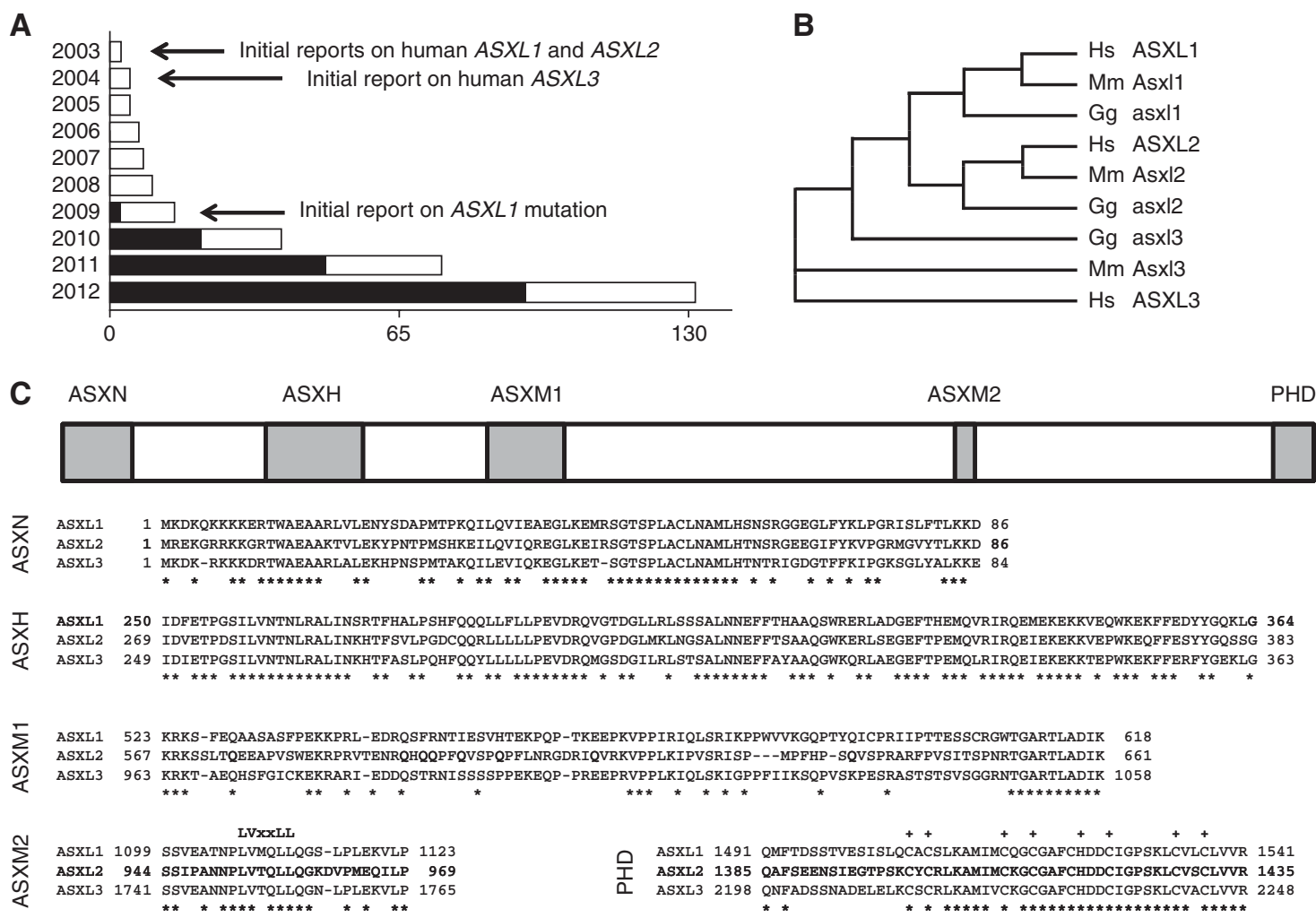

Figure 1. The ASXL family. (A) Chronology of the ASXL family. Cumulative publication numbers of ASXL1, ASXL2 or ASXL3 manuscripts in the PubMed database are shown by open bars, whereas those of ASXL1 mutations in malignant myeloid diseases are depicted with closed bars. (B) Phylogeny of the vertebrate ASXL family members. Hs, human; Gg, chicken; Mm, mouse. (C) Conserved domain architecture of the ASXL family members, consisting of the ASXN, ASXH, ASXM1, ASXM2 and PHD domains. The LVxxLL motif in the ASXM2 domain and the C4HC3 motif in the PHD domain are shown above the amino-acid alignment. The conserved amino acids are shown by asterisks below the alignment. 


\section{Table 1. Cancer genomics of the ASXL family genes}

\begin{tabular}{|c|c|c|c|}
\hline Gene & Genetic alterations & Cancer & Mutation rate \\
\hline ASXL1 & $\begin{array}{l}\text { Gene amplification } \\
\text { Truncation mutation }\end{array}$ & $\begin{array}{l}\text { Cervical cancer } \\
\text { CRC with MSI } \\
\text { CMML } \\
\text { MPN } \\
\text { AML (secondary) } \\
\text { MDS } \\
\text { Liver cancer } \\
\text { AML (de novo) } \\
\text { CLL } \\
\text { Prostate cancer } \\
\text { HNSCC } \\
\text { Breast cancer }\end{array}$ & $\begin{array}{c}4 / 79(5.1 \%) \\
6 / 11(55 \%)^{\mathrm{a}} \\
124 / 274(45.3 \%) \\
41 / 119(34.5 \%) \\
30 / 99(30 \%) \\
148 / 914(16.2 \%) \\
1 / 10(10 \%) \\
130 / 2000(6.5 \%) \\
3 / 105(2.9 \%) \\
1 / 50(2.0 \%) \\
1 / 74(1.4 \%) \\
1 / 100(1.0 \%)\end{array}$ \\
\hline ASXL2 & $\begin{array}{l}\text { Truncation mutation } \\
\text { Chromosomal } \\
\text { translocation }\end{array}$ & $\begin{array}{l}\text { Prostate cancer } \\
\text { Pancreatic cancer } \\
\text { Breast cancer } \\
\text { ATLL }\end{array}$ & $\begin{array}{l}3 / 50(6.0 \%) \\
1 / 24(4.2 \%) \\
1 / 100(1.0 \%) \\
\text { Rare }\end{array}$ \\
\hline ASXL3 & Truncation mutation & Melanoma & $1 / 25(4.0 \%)$ \\
\hline \multicolumn{4}{|c|}{ 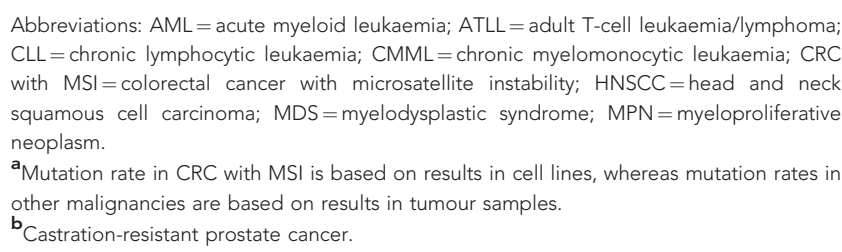 } \\
\hline
\end{tabular}

than their Asxl1 and Asxl2 orthologues. Phylogenetic analyses of the human, mouse and chicken ASXL family proteins reveal that the ASXL1 and ASXL2 orthologues are more closely related (Figure 1B).

The ASXL1, ASXL2 and ASXL3 proteins share a common domain architecture that consists of an ASXN domain in the $\mathrm{N}$-terminal region, an ASXH domain in the N-terminal adjoining region, ASXM1 and ASXM2 domains in the middle region and a PHD domain in the C-terminal region (Figure 1C).

The ASXN domain, which we first discovered in 2003 based on the homology between human ASXL1 and ASXL2 (Katoh and Katoh, 2003), is conserved among vertebrate ASXL homologues but not Drosophila Asx. The ASXN domain is structurally similar to the Forkhead-box (FOX) domain, which is also known as the winged helix-turn-helix domain, of FOXA3, FOXK1, FOXO1 and FOXO4 (Sanchez-Pulido et al, 2012). The FOX domain is the DNA-binding module of the FOX family members, which are involved in transcriptional regulation and DNA repair during embryogenesis and carcinogenesis (Katoh et al, 2013). SanchezPulido et al (2012) predicted that the ASXN domain functions as the DNA-binding module of the ASXL family members.

The region around the ASXH domain of ASXL1 directly binds to BAP1 (Scheuermann et al, 2010) and KDM1A (LSD1; Lee et al, 2010). BAP1 and UCH37/UCHL5 are de-ubiquitinating proteases that share a similar domain architecture consisting of UCH and ULD domains; the ASXH-similar domain of ADRM1/ hRpn13 and the region around the ASXH-similar domain of NFRKB/INO80G directly bind to the ULD domain of UCH37/ UCHL5 (Sanchez-Pulido et al, 2012). These facts indicate that the region around the ASXH domain is a protein-protein interaction
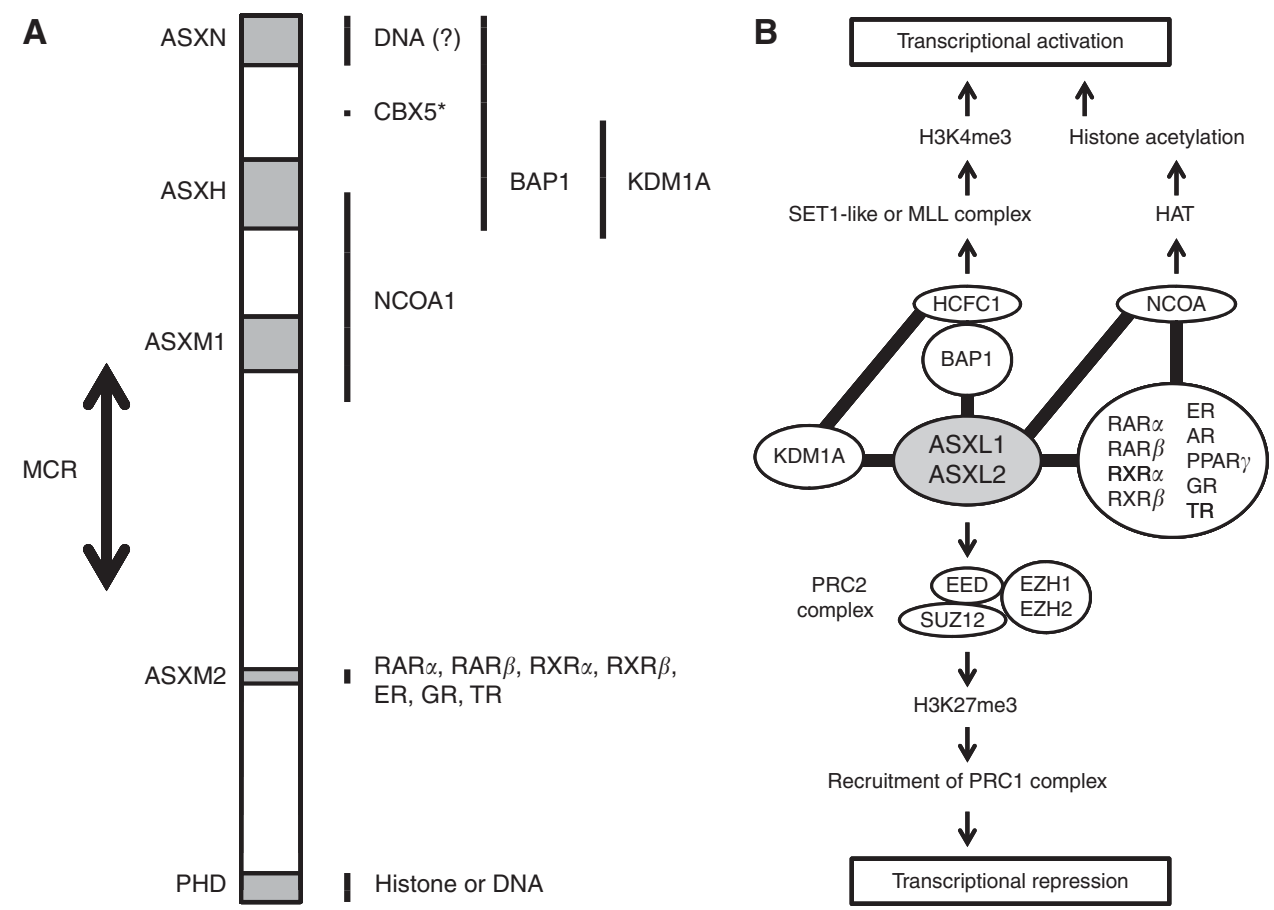

Figure 2. The ASXL network. (A) ASXL1-binding partners. The ASXN and PHD domains are binding modules for DNA or modified histones. The regions around the ASXH, ASXM1 and ASXM2 domains are binding modules for BAP1, KDM1A (LSD1), NCOA1 and NHRs, such as retinoic acid receptors and oestrogen receptor. CBX5 * indicates CBX5 binds to ASXL1, but not to ASXL2. Truncation mutations, clustered within the MCR region, give rise to aberrant $A S X L$ proteins with $A S X N$ and $A S X H$ domains. (B) Involvement of the $A S X L$ proteins in transcriptional regulation. $A S X L$ proteins assemble BAP1, KDM1A, NCOA1 and NHRs to specific genomic loci with histone modification. ASXL proteins recruit BAP1 and NHR complexes for transcriptional activation, as well as PRC for transcriptional repression. The ASXL proteins activate or repress transcription of the target genes in a context-dependent manner. 
module that associates with epigenetic regulators, such as BAP1 and KDM1A.

The ASXM1 and ASXM2 domains are also conserved among the ASXL family members (Figure 1C). The ASXM1 domain is located within the NCOA1 (SRC1)-binding region of ASXL1 (Cho et al, 2006). In contrast, the LVxxLL motif within the ASXM2 domain of ASXL1 is the binding motif for nuclear hormone receptors (NHRs), such as $\operatorname{RAR} \alpha, \operatorname{RAR} \beta, \operatorname{RXR} \alpha, \operatorname{RXR} \beta, \mathrm{ER}, \mathrm{AR}$, GR and TR (Cho et al, 2006). The ASXM1 and ASXM2 domains are protein-protein interaction modules that associate with NHRs and their cofactors.

The PHD domain, defined by a motif of four cysteine residues, one histidine residue and three cysteine residues $(\mathrm{C} 4 \mathrm{HC} 3)$, is a histone- or DNA-binding module of chromatin regulators and transcription factors (Sanchez and Zhou, 2011; Li and Li 2012; Liu et al, 2012). For example, the first PHD domain of BPTF, the third PHD domain of MLL1 and the PHD domains of ING1, PHF2, PHF8, PYGO1 and TAF3 all bind to tri- or dimethylated lysine 4 of histone $\mathrm{H} 3$ (H3K4me3/2); the first PHD domain of AIRE and the PHD domains of ATRX, DNMT3A and DNMT3L bind to unmodified lysine 4 of histone $\mathrm{H} 3(\mathrm{H} 3 \mathrm{~K} 4 \mathrm{me})$ ); the interface of the GATA-like finger and the PHD domain of ATRX binds to trimethylated lysine 9 of histone $\mathrm{H} 3$ (H3K9me3); the tandem PHD domains of KAT6A bind to acetylated lysine 14 of histone $\mathrm{H} 3$ $(\mathrm{H} 3 \mathrm{~K} 14 \mathrm{ac})$ and to unmodified arginine 2 of histone H3 (H3R2me0); the tandem PHD domains of DPF3 bind to H3K14ac and to H3K4me0/H3R2me0; the tandem PHD domains of BRPF2 bind to H3K4me0 and DNA (Sanchez and Zhou, 2011; Li and Li, 2012; Liu et al, 2012; references therein). Although the targets of the PHD domain of the ASXL family members remain to be identified, the PHD domain is predicted to be a histone- or DNA-binding module.

ASXL family proteins are divergent in non-conserved regions (Katoh and Katoh, 2003). For example, the CBX5 (HP1 $\alpha$ )-binding PxVxL motif is located between the ASXN and ASXH domains of ASXL1 and ASXL3, but is absent from the corresponding region of ASXL2 (Lee et al, 2010). CBX5 interacts with H3K9me3 and ASXL1 using the Chromo (Chromo 1) and Chromoshadow (Chromo 2) domains, respectively. Functional divergence between ASXL1 and ASXL2 occurs as a result of CBX5 interaction with ASXL1 but not with ASXL2.

The ASXN and PHD domains are putative DNA- or histonerecognition modules, whereas the middle regions around the ASXH, ASXM1 and ASXM2 domains are protein-protein interaction modules assembling BAP1, KDM1A, NCOA1 and NHRs (Figure 2A). ASXL family members are epigenetic scaffolding proteins that recruit epigenetic regulators and transcription factors to specific genomic loci with histone modifications.

\section{FUNCTION OF ASXL1}

ASXL1 assembles various proteins, such as PRC2, NHRs and BAP1, based on protein-protein interactions. ASXL1-PRC2, ASXL1-NHR and ASXL1-BAP1 are ASXL1 sub-complexes involved in epigenetic and transcriptional regulation.

ASXL1 is co-immunoprecipitated with components of PRC2, including EZH2 and SUZ12, and re-expression of ASXL1 promotes $\mathrm{H} 3 \mathrm{~K} 27 \mathrm{me} 2 / 3$ to partially inhibit the aberrant expression of the HOXA-cluster genes in ASXL1-null leukaemic cells (Abdel-Wahab et al, 2012). It remains unclear whether ASXL1 binds to a PRC2 component directly or indirectly; however, ASXL1 recruits PRC2 to specific genomic loci, where it adds the $\mathrm{H} 3 \mathrm{~K} 27 \mathrm{me} 3$ repressive mark to further recruit PRC1 for transcriptional repression (Figure 2B).

ASXL1 directly binds to NHRs, such as RARs, RXRs, ER and $\mathrm{AR}$, as well as to the NHR-coactivator NCOA1 (Cho et al, 2006;
Grasso et al, 2012). On the basis of the NCOA1-mediated recruitment of histone acetyltransferase to the ASXL1-NHR complex, ASXL1 promotes NHR-dependent transcriptional activation (Figure 2B).

ASXL1 as well as ASXL2, BRCA1, FOXK1, FOXK2, HCFC1 and YY1 are binding partners of BAP1 (Jensen et al, 1998; Sowa et al, 2009; Scheuermann et al, 2010; Yu et al, 2010; Dey et al, 2012). ASXL1, ASXL2, BRCA1 and YY1 bind to the region around the ULD domain of BAP1, whereas HCFC1 binds to the HBM motif of BAP1. BAP1, the human orthologue of the Drosophila Calypso, is a nuclear de-ubiquitinating enzyme. Polycomb repressor complex 1 is involved in the mono-ubiquitination of histone $\mathrm{H} 2 \mathrm{~A}$, whereas the human ASXL1-BAP1 complex and the Drosophila Asx-Calypso complex are involved in $\mathrm{H} 2 \mathrm{~A}$ de-ubiquitination (Scheuermann et al, 2010). The BAP1-HCFC1 complex is recruited to specific genomic loci based on interactions with BAP1-binding partners; HCFC1 then recruits SET1-like or MLL complexes for transcriptional activation via H3K4me3 (Figure 2B).

Asxl1 homozygous mutant (knock-out) mice were generated through integration of a neomycin-resistant cassette into exon 5 of the Asxll gene using homologous recombination (Fisher et al, 2010a, b). The ASXH, ASXM1, ASXM2 and PHD domains are deleted from the Asxl1 protein of these mice due to insertion of the neomycin-resistant cassette at codon 90 of mouse Asxl1. The Asxl1 knock-out mice are characterised by partial neonatal death. Newborn Asxl1 knock-out mice show posterior transformation of cervical (C7) and thoracic (T13) vertebrae, as well as anterior transformation of cervical ( $\mathrm{C} 1$ and $\mathrm{C} 2$ ) vertebrae, which correspond to the mammalian PcG and trxG phenotypes, respectively, (Fisher et al, 2010a). Adult Asxl1 knock-out mice exhibit bodyweight loss, splenomegaly and mild haematological phenotypes, such as altered differentiation frequencies of lymphoid and myeloid progenitors (Fisher et al, 2010b).

Taken together, these facts clearly indicate that ASXL1 is involved in both transcriptional activation and transcriptional repression in a context-dependent manner (Figure 2B).

\section{FUNCTION OF ASXL2}

ASXL2 promotes adipocytic differentiation of 3T3-L1 preadipocytes through enhancement of ligand-induced PPAR $\gamma$ activity, whereas ASXL1 suppresses adipogenesis through inhibition of PPAR $\gamma$ activity (Park et al, 2011). Fabp4 is a representative target of PPAR $\gamma$. ASXL2 upregulates Fabp4 transcription based on the MLL1-associated active chromatin mark H3K4me3. In contrast, ASXL1 downregulates Fabp 4 transcription based on the $\mathrm{CBX} 5$-associated repressive chromatin mark $\mathrm{H} 3 \mathrm{~K} 9 \mathrm{me} 3$. The CBX5-binding motif is absent in ASXL2 but present in ASXL1. As deletion of the CBX5-binding motif from ASXL1 results in the promotion of adipogenesis such as that associated with ASXL2, functional divergence of ASXL2 and ASXL1 is in part due to the lack of a CBX5-binding motif in ASXL2 (Park et al, 2011).

Asxl2 homozygous mutant (knock-out) mice were generated from an embryonic stem (ES) cell line, with the $\beta$-geo cassette integration into intron 1 of the Asxl2 gene (Baskind et al, 2009). The $\beta$-geo reporter protein is expressed instead of wild-type Asxl2 because of aberrant splicing from exon 1 of the Asxl2 gene, encoding the N-terminal 19 amino acids, to the gene-trap cassette. As wild-type Asxl2 splicing is not completely blocked by the genetrap cassette, the wild-type Asxl2 transcript is minimally expressed in the Asxl2 knock-out mice at a level that is $3 \%$ of control mice. The Asxl2 knock-out mice are characterised by partial embryonic lethality and premature death owing to a defect in or retardation of growth (Baskind et al, 2009). The skeletal abnormalities in the sacral and thoracic vertebrae of the Asxl2 knock-out mice are due 
to posterior transformation (PcG phenotype) and anterior transformation (trxG phenotype), respectively. The bone mineral density is significantly decreased in the Asxl2 knock-out mice, most likely due to low turnover osteopenia (Farber et al, 2011). In addition, dilated cardiomyopathy accompanied by a disarray of the cardiac myocytes and interstitial fibrosis is observed in the Asxl2 knock-out mice, owing to epigenetic aberrations associated with the decreased level of H3K27me3 (Baskind et al, 2009).

These facts indicate that Asxl2 is also involved in transcriptional activation and repression in a context-dependent manner (Figure 2B).

\section{HUMAN GENETICS OF ASXL1 AND ASXL3}

Germ-line mutations of human ASXL1 occur in Bohring-Opitz syndrome, which is characterised by mental retardation, cranioskeletal features and feeding problems (Hoischen et al, 2011). Germ-line mutations of human ASXL3 occur in a novel syndrome also characterised by mental retardation, cranio-skeletal features and feeding problems, which are partially similar to those observed in Bohring-Opitz syndrome and Cornelia de Lange syndrome (Bainbridge et al, 2013).

ASXL1 germ-line mutations are de novo nonsense or frame-shift mutations, resulting in ASXL1 truncation with loss of the NHR-binding ASXM2 domain and the C-terminal PHD domain. ASXL3 germ-line mutations are de novo nonsense or frame-shift mutations, resulting in ASXL3 truncation with loss of the ASXM1, ASXM2 and PHD domains. It is noteworthy that the ASXN and ASXH domains are retained in the truncated ASXL1 and ASXL3 mutants involved in Bohring-Opitz and similar syndromes, respectively. Epigenetic aberrations and cancer predispositions related to germ-line mutations of ASXL1 and ASXL3 remain to be elucidated.

\section{CANCER GENOMICS}

Nonsense point mutations or frame-shift mutations of ASXL1 occur in haematological malignancies, such as myelodysplastic syndrome (MDS), myeloproliferative neoplasms (MPN), MDS/ MPN, acute myeloid leukaemia (AML) and chronic lymphocytic leukaemia (CLL; Carbuccia et al, 2009; Gelsi-Boyer et al, 2009; Quesada et al, 2011). Myelodysplastic syndrome includes refractory cytopenia with unilineage dysplasia, refractory anaemia with ring sideroblasts, refractory cytopenia with multilineage dysplasia, refractory anaemia with excess blasts, $5 \mathrm{q}$-deletion syndrome and other conditions; MPN includes $B C R-A B L 1$-positive chronic myelogenous leukaemia (CML), polycythaemia vera, primary myelofibrosis, essential thrombocythaemia and other conditions; MDS/MPN includes chronic myelomonocytic leukaemia (CMML), $B C R-A B L 1$-negative CML and other conditions (Vardiman et al, 2009). Whole-exome sequencing analyses revealed that ASXL1 is mutated in 2.9\% of CLL cases (Quesada et al, 2011), whereas metaanalyses revealed that ASXL1 is mutated in $45.3 \%$ of CMML cases, $34.5 \%$ of MPN cases, $30 \%$ of secondary AML cases, $16.2 \%$ of MDS cases and 6.5\% of de novo AML cases (Gelsi-Boyer et al, 2012).

Asxl1 silencing cooperates with oncogenic NRasG12D to induce hepatosplenomegaly and progressive anaemia in mouse model experiments, emphasising the role of Asxll in myeloid malignancies (Abdel-Wahab et al, 2012). However, myeloid malignancies do not occur in Asxl1 knock-out mice (Fisher et al, 2010b). ASXL1 and ASXL2 orthologues share a common domain architecture, and mouse Asxl1 and Asxl2 are co-expressed in ES cells, in all stages of embryos and in various types of adult tissues, suggesting that the suppression of myeloid malignancies in the
Asxl1 knock-out mice might stem from a functional redundancy between Asxl1 and Asxl2. In addition, the ASXH domain is deleted from the mouse Asxl1 knock-out allele, whereas this domain is retained in the human ASXL1 truncation mutants. Human ASXL1 mutants with ASXN and ASXH domains retain the ability to assemble BAP1 and its binding partners (Figure 2), thereby resulting in aberrant epigenetic regulation. The upregulation of LRP6, CYP1B1, MAGI3 and MPP6, and the downregulation of KISS1R and MLLT10 occur in AML with mutant ASXL1, compared with AML with wild-type ASXL1 (Metzeler et al, 2011). As ASXL1 truncations in human myeloid malignancies are misregulating mutations that alter the transcriptional landscape, ASXL1 mutations are associated with a poor prognosis in patients with MDS, MPN and AML (Gelsi-Boyer et al, 2012).

ASXL1 is also frequently mutated in colorectal cancer (CRC) cell lines with microsatellite instability (MSI; Williams et al, 2010). The G8 mononucleotide repeat at nucleotide position c.1927 to c.1934 of the ASXL1 gene is susceptible to the deletion or insertion of a G nucleotide as a result of MSI. The deletion of c.1934G (c.1934delG), which causes a frame-shift (Gly645ValfsX58), occurs in 5 of 11 CRC cell lines with MSI, whereas the duplication of c.1934G (c.1934dupG), which causes a frame-shift (Gly646TrpfsX12), occurs in 1 of 11 CRC cell lines with MSI.

Truncation mutations of the ASXL family genes occur relatively infrequently in other types of human cancers (Table 1). ASXL1 and ASXL2 are mutated in $2.0 \%$ and $6.0 \%$ of castration-resistant prostate cancers, respectively, (Grasso et al, 2012). ASXL1 and ASXL2 are each mutated in $1.0 \%$ of breast cancers (Stephens et al, 2012). ASXL1 is mutated in $10 \%$ and $1.4 \%$ of liver cancers and head and neck squamous cell carcinomas, respectively, (Li et al, 2011; Stransky et al, 2011). ASXL2 is mutated in $4.2 \%$ of pancreatic cancers (Jones et al, 2008) and ASXL3 is mutated in $4.0 \%$ of melanomas (Berger et al, 2012).

EPC1-ASXL2 gene fusion occurs in adult T-cell leukaemia/ lymphoma because of a $\operatorname{der}(10) \mathrm{t}(2 ; 10)(\mathrm{p} 23 ; \mathrm{p} 11.2)$ translocation (Nakahata et al, 2009). As the putative DNA-binding domain of ASXL2 is substituted by an SRF/RING1A-binding region in the EPC1-ASXL2 fusion protein, the EPC1-ASXL2 gene fusion disrupts the function of wild-type ASXL2.

Gene amplification accompanied by overexpression of the amplified gene product is one of the mechanisms for activation of a proto-oncogene. ASXL1 is amplified and overexpressed in $5.1 \%$ of cervical cancers (Scotto et al, 2008).

\section{CONCLUSION}

ASXL1, ASXL2 and ASXL3 are human homologues of Drosophila Asx. The ASXL proteins directly interact with BAP1, KDM1A, NHRs and NCOA1 to target specific genomic loci using histone modifications. ASXL1 is involved in transcriptional repression based on the recruitment of PRC2, and also in transcriptional regulation based on the recruitment of NHR and/or BAP1 complexes. Bifunctional effects on transcriptional regulation are evolutionarily conserved between mammalian ASXL family members and Drosophila Asx. Gene amplification, chromosomal translocation and truncation mutations of ASXL family members occur in various types of human cancers (Table 1).

Perspectives. How are the ASXL family members recruited to specific genomic loci? ASXLs are indirectly recruited to NHRbinding regions through their interactions with NHRs and are potentially recruited to specific genomic regions with histone modifications using their ASXN and PHD domains (Figure 2A). The ASXN domain is conserved among vertebrate ASXL family members, but that conservation does not extend to Drosophila Asx (Katoh and Katoh, 2003; Katoh and Katoh, 2004), which might 
lead to a functional divergence of the ASXL homologues between vertebrates and Drosophila owing to an altered recognition of the target loci. The ASXL-binding genomic loci in various types of human cells should be systematically investigated using a chromatin-immunoprecipitation assay combined with nextgeneration sequencing analysis.

ASXL1 is amplified and overexpressed in cervical cancer. Overexpressed ASXL1 could recruit the BAP1-HCFC1 complex for the transcriptional activation of proto-oncogenes or PRC2 for the transcriptional repression of tumour suppressor genes. Functional reports on ASXL1 amplification in cervical cancer or other types of squamous cell carcinomas are necessary to further understand the oncogenic potential of ASXL1 overexpression.

The ASXL1 mutation rate is $3.2 \%$ in cytogenetically normal AML (CN-AML) patients who are younger than 60 years of age, but $16.2 \%$ in CN-AML patients who are 60 years of age or older (Metzeler et al, 2011), indicating that ASXL1 mutations are detected preferentially in older patients. As the expression of Asxl1 mRNA is significantly decreased in the brains of 18-month-old mice compared with that in the brains of 1-month-old mice (Jee et al, 2007), the expression of wild-type ASXL1 mRNA might also be decreased in the malignant myeloid cells of older patients. Alternatively, microdeletion might preferentially occur in the wild-type ASXL1 allele of older CN-AML patients as a result of the longer period that has elapsed following the acquisition of the ASXL1 truncation mutation. The promoter methylation status and copy-number aberrations of the ASXL1 gene need to be investigated because epigenetic silencing or deletion of the wildtype allele might be involved in the preferential detection of ASXL1 mutations in older patients.

ASXL1 truncation mutations occur relatively frequently in CRC cell lines with MSI and in clinical samples of myeloid malignancies (Table 1). The coding G8 microsatellite (c.1927 to c.1934) of the ASXL1 gene is susceptible to insertion or deletion of a $\mathrm{G}$ nucleotide (c.1934dupG or c.1934delG) in CRC with MSI (Williams et al, 2010), whereas the c.1934dupG mutation is the most frequent ASXL1 mutation in myeloid malignancies (Gelsi-Boyer et al, 2012). As the c.1934dupG ASXL1 mutation was identified as one of transcripts resistant to nonsense-mediated decay in CRC with MSI, the ASXL1 mutant protein derived from the c.1934dupG allele is predicted to be expressed as a C-terminally truncated protein. The contribution of MSI to the ASXL1 truncation mutation in myeloid malignancies should be further investigated.

Somatic mutations of BAP1 also occur in various types of human malignancies, and loss of BAP1 causes myeloid transformation (Dey et al, 2012). The ASXL family members, by interacting with BAP1, NHR and PRC complexes, are predicted to be tumour suppressive or oncogenic in a context-dependent manner. Integrative analyses of various types of human cancers are necessary to determine the $A S X L$-mutation landscape and to understand the consequent network aberrations as a platform for ASXL-targeted cancer therapeutics.

\section{ACKNOWLEDGEMENTS}

This study was supported in part by the National Cancer Centre Research and Development Fund.

\section{CONFLICT OF INTEREST}

The author declares no conflict of interest.

\section{REFERENCES}

Abdel-Wahab O, Adli M, LaFave LM, Gao J, Hricik T, Shih AH, Pandey S, Patel JP, Chung YR, Koche R, Perna F, Zhao X, Taylor JE, Park CY, Carroll M, Melnick A, Nimer SD, Jaffe JD, Aifantis I, Bernstein BE, Levine RL (2012) ASXL1 mutations promote myeloid transformation through loss of PRC2-mediated gene repression. Cancer Cell 22: 180-193.

Bainbridge MN, Hu H, Muzny DM, Musante L, Lupski JR, Graham BH, Chen W, Gripp KW, Jenny K, Wienker TF, Yang Y, Sutton VR, Gibbs RA, Ropers HH (2013) De novo truncating mutations in ASXL3 are associated with a novel clinical phenotype with similarities to Bohring-Opitz syndrome. Genome Med 5: 11.

Baskind HA, Na L, Ma Q, Patel MP, Geenen DL, Wang QT (2009) Functional conservation of Asxl2, a murine homolog for the Drosophila enhancer of trithorax and polycomb group gene Asx. PLoS One 4: e4750.

Berger MF, Hodis E, Heffernan TP, Deribe YL, Lawrence MS, Protopopov A, Ivanova E, Watson IR, Nickerson E, Ghosh P, Zhang H, Zeid R, Ren X, Cibulskis K, Sivachenko AY, Wagle N, Sucker A, Sougnez C, Onofrio R, Ambrogio L, Auclair D, Fennell T, Carter SL, Drier Y, Stojanov P, Singer MA, Voet D, Jing R, Saksena G, Barretina J, Ramos AH, Pugh TJ, Stransky N, Parkin M, Winckler W, Mahan S, Ardlie K, Baldwin J, Wargo J, Schadendorf D, Meyerson M, Gabriel SB, Golub TR, Wagner SN, Lander ES, Getz G, Chin L, Garraway LA (2012) Melanoma genome sequencing reveals frequent PREX2 mutations. Nature 485: 502-506.

Bischoff K, Ballew AC, Simon MA, O’Reilly AM (2009) Wing defects in Drosophila xenicid mutant clones are caused by C-terminal deletion of additional sex combs (Asx). PLoS One 4: e8106.

Breen TR, Duncan IM (1986) Maternal expression of genes that regulate the bithorax complex of Drosophila melanogaster. Dev Biol 118: 442-456.

Brock HW, Fisher CL (2005) Maintenance of gene expression patterns. Dev Dyn 232: 633-655.

Brock HW, van Lohuizen M (2001) The Polycomb group: no longer an exclusive club? Curr Opin Genet Dev 11: 175-181.

Campbell RB, Sinclair DA, Couling M, Brock HW (1995) Genetic interactions and dosage effects of Polycomb group genes of Drosophila. Mol Gen Genet 246: 291-300.

Carbuccia N, Murati A, Trouplin V, Brecqueville M, Adélaïde J, Rey J, Vainchenker W, Bernard OA, Chaffanet M, Vey N, Birnbaum D, Mozziconacci MJ (2009) Mutations of ASXL1 gene in myeloproliferative neoplasms. Leukemia 23: 2183-2186.

Cheng NN, Sinclair DA, Campbell RB, Brock HW (1994) Interactions of polyhomeotic with Polycomb group genes of Drosophila melanogaster. Genetics 138: 1151-1162.

Cho YS, Kim EJ, Park UH, Sin HS, Um SJ (2006) Additional sex comb-like 1 (ASXL1), in cooperation with SRC-1, acts as a ligand-dependent coactivator for retinoic acid receptor. J Biol Chem 28: 17588-17598.

Dey A, Seshasayee D, Noubade R, French DM, Liu J, Chaurushiya MS, Kirkpatrick DS, Pham VC, Lill JR, Bakalarski CE, Wu J, Phu L, Katavolos P, LaFave LM, Abdel-Wahab O, Modrusan Z, Seshagiri S, Dong K, Lin Z, Balazs M, Suriben R, Newton K, Hymowitz S, Garcia-Manero G, Martin F, Levine RL, Dixit VM (2012) Loss of the tumor suppressor BAP1 causes myeloid transformation. Science 337: 1541-1546.

Dietrich BH, Moore J, Kyba M, dosSantos G, McCloskey F, Milne TA, Brock HW, Krause HM (2001) Tantalus, a novel ASX-interacting protein with tissue-specific functions. Dev Biol 234: 441-453.

Farber CR, Bennett BJ, Orozco L, Zou W, Lira A, Kostem E, Kang HM, Furlotte N, Berberyan A, Ghazalpour A, Suwanwela J, Drake TA, Eskin E, Wang QT, Teitelbaum SL, Lusis AJ (2011) Mouse genome-wide association and systems genetics identify Asxl2 as a regulator of bone mineral density and osteoclastogenesis. PLoS Genet 7: e1002038.

Fisher CL, Berger J, Randazzo F, Brock HW (2003) A human homolog of Additional sex combs, ADDITIONAL SEX COMBS-LIKE 1, maps to chromosome 20q11. Gene 306: 115-126.

Fisher CL, Lee I, Bloyer S, Bozza S, Chevalier J, Dahl A, Bodner C, Helgason CD, Hess JL, Humphries RK, Brock HW (2010a) Additional sex combs-like 1 belongs to the enhancer of trithorax and polycomb group and genetically interacts with Cbx2 in mice. Dev Biol 337: 9-15.

Fisher CL, Pineault N, Brookes C, Helgason CD, Ohta H, Bodner C, Hess JL, Humphries RK, Brock HW (2010b) Loss-of-function Additional sex combs like 1 mutations disrupt hematopoiesis but do not cause severe myelodysplasia or leukemia. Blood 115: 38-46. 
Gelsi-Boyer V, Brecqueville M, Devillier R, Murati A, Mozziconacci MJ, Birnbaum D (2012) Mutations in ASXL1 are associated with poor prognosis across the spectrum of malignant myeloid diseases. J Hematol Oncol 5: 12.

Gelsi-Boyer V, Trouplin V, Adélaïde J, Bonansea J, Cervera N, Carbuccia N, Lagarde A, Prebet T, Nezri M, Sainty D, Olschwang S, Xerri L, Chaffanet M, Mozziconacci MJ, Vey N, Birnbaum D (2009) Mutations of polycomb-associated gene ASXL1 in myelodysplastic syndromes and chronic myelomonocytic leukaemia. Br J Haematol 145: 788-800.

Gildea JJ, Lopez R, Shearn A (2000) A screen for new trithorax group genes identified little imaginal discs, the Drosophila melanogaster homologue of human retinoblastoma binding protein 2. Genetics 156: 645-663.

Grasso CS, Wu YM, Robinson DR, Cao X, Dhanasekaran SM, Khan AP, Quist MJ, Jing X, Lonigro RJ, Brenner JC, Asangani IA, Ateeq B, Chun SY, Siddiqui J, Sam L, Anstett M, Mehra R, Prensner JR, Palanisamy N, Ryslik GA, Vandin F, Raphael BJ, Kunju LP, Rhodes DR, Pienta KJ, Chinnaiyan AM, Tomlins SA (2012) The mutational landscape of lethal castration-resistant prostate cancer. Nature 487: 239-243.

Grimaud C, Nègre N, Cavalli G (2006) From genetics to epigenetics: the tale of Polycomb group and trithorax group genes. Chromosome Res 14: 363-375.

Halachmi N, Schulze KL, Inbal A, Salzberg A (2007) Additional sex combs affects antennal development by means of spatially restricted repression of Antp and wg. Dev Dyn 236: 2118-2130.

Hoischen A, van Bon BW, Rodríguez-Santiago B, Gilissen C, Vissers LE, de Vries P, Janssen I, van Lier B, Hastings R, Smithson SF, Newbury-Ecob R, Kjaergaard S, Goodship J, McGowan R, Bartholdi D, Rauch A, Peippo M, Cobben JM, Wieczorek D, Gillessen-Kaesbach G, Veltman JA, Brunner HG, de Vries BB (2011) De novo nonsense mutations in ASXL1 cause Bohring-Opitz syndrome. Nat Genet 43: 729-731.

Jee SW, Cho JS, Kim CK, Hwang DY, Shim SB, Lee SH, Sin JS, Kim YS, Park JH, Lee SH, Choi SY, Kim YK (2007) Analysis of differentially expressed genes in early- and late-stage APPsw-transgenic and normal mice using cDNA microarray. Int J Mol Med 19: 461-468.

Jensen DE, Proctor M, Marquis ST, Gardner HP, Ha SI, Chodosh LA, Ishov AM, Tommerup N, Vissing H, Sekido Y, Minna J, Borodovsky A, Schultz DC, Wilkinson KD, Maul GG, Barlev N, Berger SL, Prendergast GC, Rauscher 3rd FJ (1998) BAP1: a novel ubiquitin hydrolase which binds to the BRCA1 RING finger and enhances BRCA1-mediated cell growth suppression. Oncogene 16: 1097-1112.

Jones S, Zhang X, Parsons DW, Lin JC, Leary RJ, Angenendt P, Mankoo P, Carter H, Kamiyama H, Jimeno A, Hong SM, Fu B, Lin MT, Calhoun ES, Kamiyama M, Walter K, Nikolskaya T, Nikolsky Y, Hartigan J, Smith DR, Hidalgo M, Leach SD, Klein AP, Jaffee EM, Goggins M, Maitra A, Iacobuzio-Donahue C, Eshleman JR, Kern SE, Hruban RH, Karchin R, Papadopoulos N, Parmigiani G, Vogelstein B, Velculescu VE, Kinzler KW (2008) Core signaling pathways in human pancreatic cancers revealed by global genomic analyses. Science 321: 1801-1806.

Jürgens G (1985) A group of genes controlling the spatial expression of the bithorax complex in Drosophila. Nature 316: 153-155.

Katoh M, Igarashi M, Fukuda H, Nakagama H, Katoh M (2013) Cancer genetics and genomics of human FOX family genes. Cancer Lett 328: 198-206.

Katoh M, Katoh M (2003) Identification and characterization of ASXL2 gene in silico. Int J Oncol 23: 845-850.

Katoh M, Katoh M (2004) Identification and characterization of ASXL3 gene in silico. Int J Oncol 24: 1617-1622.

Lee SW, Cho YS, Na JM, Park UH, Kang M, Kim EJ, Um SJ (2010) ASXL1 represses retinoic acid receptor-mediated transcription through associating with HP1 and LSD1. J Biol Chem 285: 18-29.

Li M, Zhao H, Zhang X, Wood LD, Anders RA, Choti MA, Pawlik TM, Daniel HD, Kannangai R, Offerhaus GJ, Velculescu VE, Wang L, Zhou S, Vogelstein B, Hruban RH, Papadopoulos N, Cai J, Torbenson MS, Kinzler KW (2011) Inactivating mutations of the chromatin remodeling gene ARID2 in hepatocellular carcinoma. Nat Genet 43: 828-829.

Li Y, Li H (2012) Many keys to push: diversifying the 'readership' of plant homeodomain fingers. Acta Biochim Biophys Sin 44: 28-39.

Liu L, Qin S, Zhang J, Ji P, Shi Y, Wu J (2012) Solution structure of an atypical PHD finger in BRPF2 and its interaction with DNA. J Struct Biol 180: 165-173.

Metzeler KH, Becker H, Maharry K, Radmacher MD, Kohlschmidt J, Mrózek K, Nicolet D, Whitman SP, Wu YZ, Schwind S, Powell BL, Carter TH, Wetzler M, Moore JO, Kolitz JE, Baer MR, Carroll AJ, Larson RA, Caligiuri MA, Marcucci G, Bloomfield CD (2011) ASXL1 mutations identify a high-risk subgroup of older patients with primary cytogenetically normal AML within the ELN favorable genetic category. Blood 118: 6920-6929.

Milne TA, Sinclair DA, Brock HW (1999) The Additional sex combs gene of Drosophila is required for activation and repression of homeotic loci, and interacts specifically with Polycomb and super sex combs. Mol Gen Genet 261: 753-761.

Müller J, Verrijzer P (2009) Biochemical mechanisms of gene regulation by polycomb group protein complexes. Curr Opin Genet Dev 19: $150-158$.

Nakahata S, Saito Y, Hamasaki M, Hidaka T, Arai Y, Taki T, Taniwaki M, Morishita K (2009) Alteration of enhancer of polycomb 1 at 10p11.2 is one of the genetic events leading to development of adult T-cell leukemia/ lymphoma. Genes Chromosomes Cancer 48: 768-776.

Park UH, Yoon SK, Park T, Kim EJ, Um SJ (2011) Additional sex comb-like (ASXL) proteins 1 and 2 play opposite roles in adipogenesis via reciprocal regulation of peroxisome proliferator-activated receptor $\gamma$. J Biol Chem 286: $1354-1363$.

Petruk S, Smith ST, Sedkov Y, Mazo A (2008) Association of trxG and PcG proteins with the $b x d$ maintenance element depends on transcriptional activity. Development 135: 2383-2390.

Pietersen AM, van Lohuizen M (2008) Stem cell regulation by polycomb repressors: postponing commitment. Curr Opin Cell Biol 20: 201-207.

Quesada V, Conde L, Villamor N, Ordóñez GR, Jares P, Bassaganyas L, Ramsay AJ, Beà S, Pinyol M, Martínez-Trillos A, López-Guerra M, Colomer D, Navarro A, Baumann T, Aymerich M, Rozman M, Delgado J, Giné E, Hernández JM, González-Díaz M, Puente DA, Velasco G, Freije JM, Tubío JM, Royo R, Gelpí JL, Orozco M, Pisano DG, Zamora J, Vázquez M, Valencia A, Himmelbauer H, Bayés M, Heath S, Gut M, Gut I, Estivill X, López-Guillermo A, Puente XS, Campo E, López-Otín C (2011) Exome sequencing identifies recurrent mutations of the splicing factor SF3B1 gene in chronic lymphocytic leukemia. Nat Genet 44: $47-52$.

Sanchez R, Zhou MM (2011) The PHD finger: a versatile epigenome reader. Trends Biochem Sci 36: 364-372.

Sanchez-Pulido L, Kong L, Ponting CP (2012) A common ancestry for BAP1 and Uch37 regulators. Bioinformatics 28: 1953-1956.

Scheuermann JC, de Ayala Alonso AG, Oktaba K, Ly-Hartig N, McGinty RK, Fraterman S, Wilm M, Muir TW, Müller J (2010) Histone H2A deubiquitinase activity of the Polycomb repressive complex PR-DUB. Nature 465: 243-247.

Schuettengruber B, Chourrout D, Vervoort M, Leblanc B, Cavalli G (2007) Genome regulation by polycomb and trithorax proteins. Cell 128: 735-745.

Schwartz YB, Pirrotta V (2007) Polycomb silencing mechanisms and the management of genomic programmes. Nat Rev Genet $\mathbf{8}$ : $9-22$.

Scotto L, Narayan G, Nandula SV, Arias-Pulido H, Subramaniyam S, Schneider A, Kaufmann AM, Wright JD, Pothuri B, Mansukhani M, Murty VV (2008) Identification of copy number gain and overexpressed genes on chromosome arm $20 \mathrm{q}$ by an integrative genomic approach in cervical cancer: potential role in progression. Genes Chromosomes Cancer 47: 755-765.

Simon J, Chiang A, Bender W (1992) Ten different Polycomb group genes are required for spatial control of the $a b d A$ and $A b d B$ homeotic products. Development 114: 493-505.

Simon J, Chiang A, Bender W, Shimell MJ, O'Connor M (1993) Elements of the Drosophila bithorax complex that mediate repression by Polycomb group products. Dev Biol 158: 131-144.

Simon JA, Kingston RE (2009) Mechanisms of Polycomb gene silencing: knowns and unknowns. Nat Rev Mol Cell Biol 10: 697-708.

Sinclair DA, Campbell RB, Nicholls F, Slade E, Brock HW (1992) Genetic analysis of the Additional sex combs locus of Drosophila melanogaster. Genetics 130: 817-825.

Sinclair DA, Milne TA, Hodgson JW, Shellard J, Salinas CA, Kyba M, Randazzo F, Brock HW (1998) The Additional sex combs gene of Drosophila encodes a chromatin protein that binds to shared and unique Polycomb group sites on polytene chromosomes. Development 125: $1207-1216$

Sowa ME, Bennett EJ, Gygi SP, Harper JW (2009) Defining the human deubiquitinating enzyme interaction landscape. Cell 138: 389-403.

Sparmann A, van Lohuizen M (2006) Polycomb silencers control cell fate, development and cancer. Nat Rev Cancer 6: 846-856. 
Stephens PJ, Tarpey PS, Davies H, Van Loo P, Greenman C, Wedge DC, Nik-Zainal S, Martin S, Varela I, Bignell GR, Yates LR, Papaemmanuil E, Beare D, Butler A, Cheverton A, Gamble J, Hinton J, Jia M, Jayakumar A, Jones D, Latimer C, Lau KW, McLaren S, McBride DJ, Menzies A, Mudie L, Raine K, Rad R, Chapman MS, Teague J, Easton D, Langerød A, Oslo Breast Cancer Consortium (OSBREAC), Lee MT, Shen CY, Tee BT, Huimin BW, Broeks A, Vargas AC, Turashvili G, Martens J, Fatima A, Miron P, Chin SF, Thomas G, Boyault S, Mariani O, Lakhani SR, van de Vijver M, van 't Veer L, Foekens J, Desmedt C, Sotiriou C, Tutt A, Caldas C, Reis-Filho JS, Aparicio SA, Salomon AV, Børresen-Dale AL, Richardson AL, Campbell PJ, Futreal PA, Stratton MR. (2012) The landscape of cancer genes and mutational processes in breast cancer. Nature 486: 400-404.

Stransky N, Egloff AM, Tward AD, Kostic AD, Cibulskis K, Sivachenko A, Kryukov GV, Lawrence MS, Sougnez C, McKenna A, Shefler E, Ramos AH, Stojanov P, Carter SL, Voet D, Cortés ML, Auclair D, Berger MF, Saksena G, Guiducci C, Onofrio RC, Parkin M, Romkes M, Weissfeld JL, Seethala RR, Wang L, Rangel-Escareño C, Fernandez-Lopez JC, Hidalgo-Miranda A, Melendez-Zajgla J, Winckler W, Ardlie K, Gabriel SB, Meyerson M, Lander ES, Getz G, Golub TR, Garraway LA, Grandis JR (2011) The mutational landscape of head and neck squamous cell carcinoma. Science 333: 1157-1160.
Tefferi A (2010) Novel mutations and their functional and clinical relevance in myeloproliferative neoplasms: JAK2, MPL, TET2, ASXL1, CBL, IDH and IKZF1. Leukemia 24: 1128-1138.

Vardiman JW, Thiele J, Arber DA, Brunning RD, Borowitz MJ, Porwit A, Harris NL, Le Beau MM, Hellström-Lindberg E, Tefferi A, Bloomfield CD (2009) The 2008 revision of the World Health Organization (WHO) classification of myeloid neoplasms and acute leukemia: rationale and important changes. Blood 114: 937-951.

Williams DS, Bird MJ, Jorissen RN, Yu YL, Walker F, Zhang HH, Nice EC, Burgess AW (2010) Nonsense mediated decay resistant mutations are a source of expressed mutant proteins in colon cancer cell lines with microsatellite instability. PLoS One 5: e16012.

Yu H, Mashtalir N, Daou S, Hammond-Martel I, Ross J, Sui G, Hart GW, Rauscher 3rd FJ, Drobetsky E, Milot E, Shi Y, Affar EB (2010) The ubiquitin carboxyl hydrolase BAP1 forms a ternary complex with YY1 and HCF-1 and is a critical regulator of gene expression. Mol Cell Biol 30: 5071-5085.

(c) (1)(2) This work is licensed under the Creative Commons (c) Attribution-NonCommercial-Share Alike 3.0 Unported License. To view a copy of this license, visit http://creativecommons. org/licenses/by-nc-sa/3.0/ 